\title{
Immunohistochemical Determination of Osteopontin Expression in Neoplastic Cells
}

\author{
Toshiyuki Kawakami, Akihiro Kimura, Hiromasa Hasegawa and Shigeo Eda \\ Department of Oral Pathology, Matsumoto Dental University School of Dentistry, Shiojiri, Japan
}

\begin{abstract}
Kawakami T, Kimura A, Hasegawa $H$ and Eda S: Immunohistochemical determination of osteopontin expresson in neoplastic cells. Oral Med Pathol 1998; 3: 75 78 ISSN 1342-0984

During our routine examination for surgical pathology of oral neoplasms, we found a case of basal cell adenoma with microcalcifications in tumoral stroma. Histopathology showed a tumor mass, covered with a thin fibrous connective tissue, and composed of cuboidal and/or columnar cells with round to ovoid nuclei. In parts of the intercellular stroma, numerous von Kossa's positive small granules were found. Under scanning electron microscopic observation, many small round granules in the stromal tissue were recognized. EPMA revealed that the granules consisted mainly of calcium and phosphorus. Immunohistochemistry showed the expression of osteopontin in the cytoplasm of neoplastic cells. Therefore, we thought that the osteopontin might have some role in the stromal microcalcification in this case of basal cell adenoma.
\end{abstract}

Key words: basal cell adenoma, microcalcification, osteopontin, immunohistochemistry, electron microscopy, pathological calcification

Correspondence: Toshiyuki Kawakami, Department of Oral Pathology, Matsumoto Dental University School of Dentistry, 1780 Gobara, Hirooka, Shiojiri, Nagano 399-0781, Japan

E-mail address: kawakami @ po. mdu. ac.jp

\section{Introduction}

Pathological microcalcifications sometimes occur in varied neoplastic tissues. We have previously examined electron microscopically the pathological microcalcifications in some oral neoplasms (1-4). This type of microcalcification is characterized as laminated granules and/or globules. Under electron microscopic observation of our examinations $(3,4)$, we considered these microcalcifications, especially those in salivary grand neoplasms, were closely related to the membranous structures, cell debris and/or secretory substances, which may elicit the calcification.

Recently there has been some literature regarding the relationship between the osteopontin and pathological calcification (5). Therefore, the purpose of the present paper is to present the results of our observations of a case of basal cell adenoma with stromal microcalcification, based on histopathological, histochemical, immunohistochemical and electron microscopic examinations and to discuss the relationship between the osteopontin and the pathological microcalcifications.

\section{Materials and Methods}

Salivary gland neoplasm materials examined in this study were obtained from the biopsy materials treated in our department. The main examination material in this paper was a neoplasm, located in the right sublingual region and in $2.3 \times 1.7 \times 1.2 \mathrm{~cm}$ in size, which was surgically removed from a 56 -year-old male patient (1). The specimens were fixed in $10 \%$ formalin solution, dehydrated by ethanol, and then embedded in paraffin. After sectioning, the specimens were stained with the following reagents: hematoxylin-eosin ( H-E), periodic acid Schiff (PAS), alcian blue, von Kossa's, and Pap's silver impregnation stain.

For immunohistochemistry, osteopontin was stained using anti-osteopontin-antibody (MPIIIB 10(1): DSHB, Iowa University, Iowa, IA, USA) at a dilution of $1 / 50$. The paraffin sections were immunostained with the Labelled Streptavidin Biotin method (LSAB Kit K 680, Dako Japan, Kyoto, Japan) and counterstained with methyl green. Negative control included inmmunostaining using PBS as a primary antibody.

For scanning electron microscopy, the selected specimens were immediately fixed in ice-cold Karnovsky's solution processed by critical-point drying, and coated with carbon by cathodic sputtering. These specimens were examined under a JCXA 733 scanning electron microscope with an EDS. 


\section{Results}

We have examined salivary gland neoplasms and immunohistochemically detected the osteopontin expression in a case of basal cell adenoma. Therefore, in this present results section, we describe only the case which has microcalcifications in the tumoral stromal tissue.

\section{Histopathological and histochemical examination}

Histopathology revealed that the tumor was encapsulated by fibrous connective tissue and demarcated from the surrounding tissues. It consisted of monomorphic epithelial cells showing a trabecular or solid pattern (Fig. 1). The solid nests were composed of basaloid epithelial

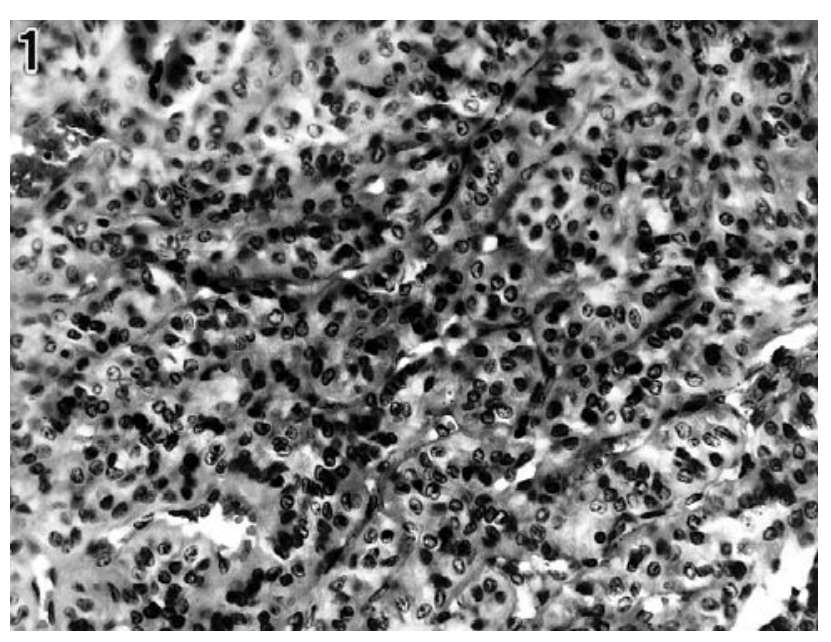

Fig.1: Proliferation of monomorphic epithelial neoplastic cells showing trabecular or solid pattern $(\mathrm{H}-\mathrm{E}, \times 200)$

cells that were columnar or cuboidal in shape with scanty eosinophilic cytoplasm and round or ovoid nuclei. Ducts and/or cystic spaces were rare and observed only at the periphery of the mass. The intercellular stroma surrounding the epithelial tumor nests was composed of thin fibrous tissue, which was noted in sections stained with Pap's silver impregnation (Fig.2). These epithelial cell nests were separated from each other by basal membranes, which stained slightly with PAS. The small von Kossa-positive granules were seen in the intercellular stroma along with the basal membrane of the tumor cell nests (Fig.3).

\section{Immunohistochemical examination}

Immunohistochemical localization of osteopontin was strongly detected mainly in the cytoplasm of the neoplastic cells of the tumor cell nests (Fig.4) and in some stromal cells, suggesting endothelial cells (Fig.5, arrows). There were no immunostaining-positive macrophages in the stromal tissues. Furthermore, there were no immunohistochemical reactions in negative controls.

\section{Electron microscopic examination}

Examination using scaning electron microscope under low magnification of secondary electron images revealed the sectioned surface of the tumor to be relatively solid. The composition images showed several light spots thought to be the same as the von Kossa-positive granules distributed in the intercellular stromal tissues. Higher magnification of the "spots" revealed that they were composed of a lots of globules, which varied in size (Fig.6). The globules were calcified as judged from their composition and radiograph ( $\mathrm{Ca}-\mathrm{K} \alpha$ ) images (Fig.7). Electron probe microanalysis demonstrated that the calcified lesion consisted mainly of calcium and phosphorus, indicating them to be calcium phosphate (Fig.8).

\section{Discussion}

Microcalcifications are a common phenomenon associated with salivary gland neoplasms. We have already studied the ultrastructure of the microcalcificatons in oral neoplasms (4), especially in salivary gland neoplasms $(1,2)$ have discussed the formation mechanism.

As noted in recently published literature (6-13), osteopontin is a phosphorylated, sialic acid-rich, noncollagenous bone matrix protein containing the Arg-Gly-AspSer amino acid sequence responsible for cell adhesion (6). The distribution of osteopontin suggests that it serves multiple functions. Although its precise function are poorly understood, osteopontin has been shown to promote attachment and spreading of variety of cell types through its Arg-Gly-Asp-Ser cell binding domain. Thus, osteopontin can be classified as an adhesive protein (13). The protein also strongly binds to calcium phosphate and plays an important role in calcification. Therefore, many researchers have studied the expression of osteopontin in varied tissues. Hirata et al. (5) reported that osteopontin was localized in necrotic foci within cancer cell nests of the breast, where calcium phosphate is deposited. The osteopontin mRNA-expressing cells were identified as macrophages. Therefore, they concluded that the osteopontin, produced by macrophages, was considered to play a significant role for development of calcifying foci within the necrotic area of the cancer. Furthermore, Brown et al. (13) examined human carcinoma tissues in varied kinds of organs, and concluded as follows: osteopontin is markedly increased in a wide variety of common human carcinomas; in carcinomas, macrophages in close proximity to tumor cells were found to be the only detectable source of osteopontin transcript, although the authors observed the labeling of tumor cells as well as macrophages.

According to the above discussions, there have been many papers regarding the osteopontin expression in the tumoral tissues, and the expression of osteopontin sites are almost all macrophages in the tumoral stromal tissues (10-12). Some are closely related with microcalcifications. But there are few descriptions of the osteopontin expression in neoplastic cells (13).

In the present study, we detected the osteopontin expression in neoplastic cells, but not in stromal macrophages, in a case of basal cell adenoma with numerous stromal microcalcifications. We think the osteopontin expression is closely related to the stromal microcalcifications, although the distribution pattern of osteopontin in 

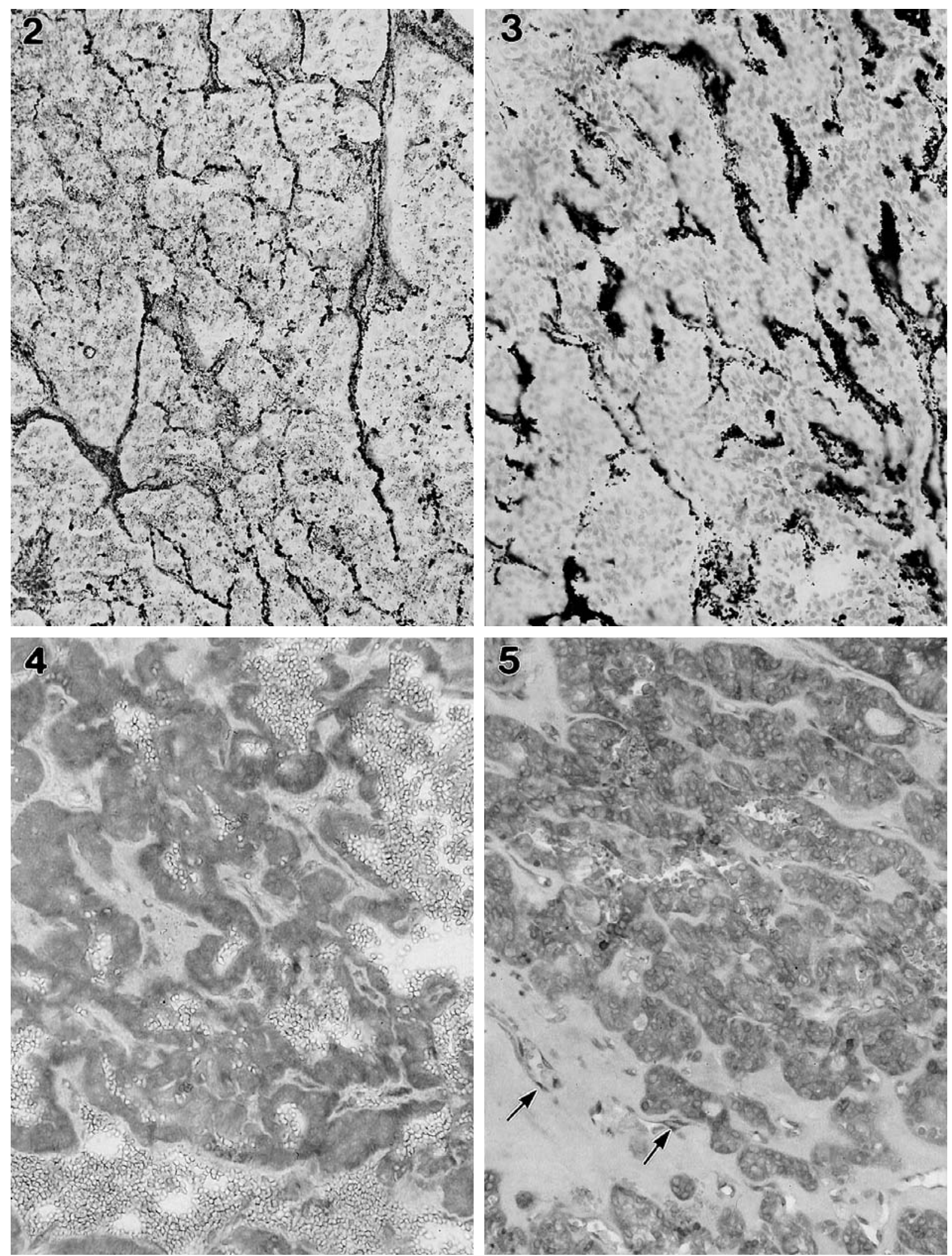

Fig.2: Scanty intercellular stroma showing silver impregnation-positive strands (Pap's silver impregnation, $\times 200$ ) Fig.3: Von Kossa-positive granules in the intercellular stroma (von Kossa's stain, $\times 200$ )

Fig.4: Expression of osteopontin was detected in the cytoplasm of the neoplastic cells. (Osteopontin immunostaining, $\times 200$ )

Fig.5: Osteopontin expression was observed in some endothelial cells (arrows). (Osteopontin immunostaining, $\times 200$ )

tumor cells with stromal calcifications were different from those of published cases (10-12). Furthermore, in the present examination case, we detected positive reactions in the endothelial cells. But there were few published data the distribution of osteopontin in the endothelial cells (9). Therefore, further histochemical and in situ hybridization examinations are in progress, and the results will be reported on in the near future. 

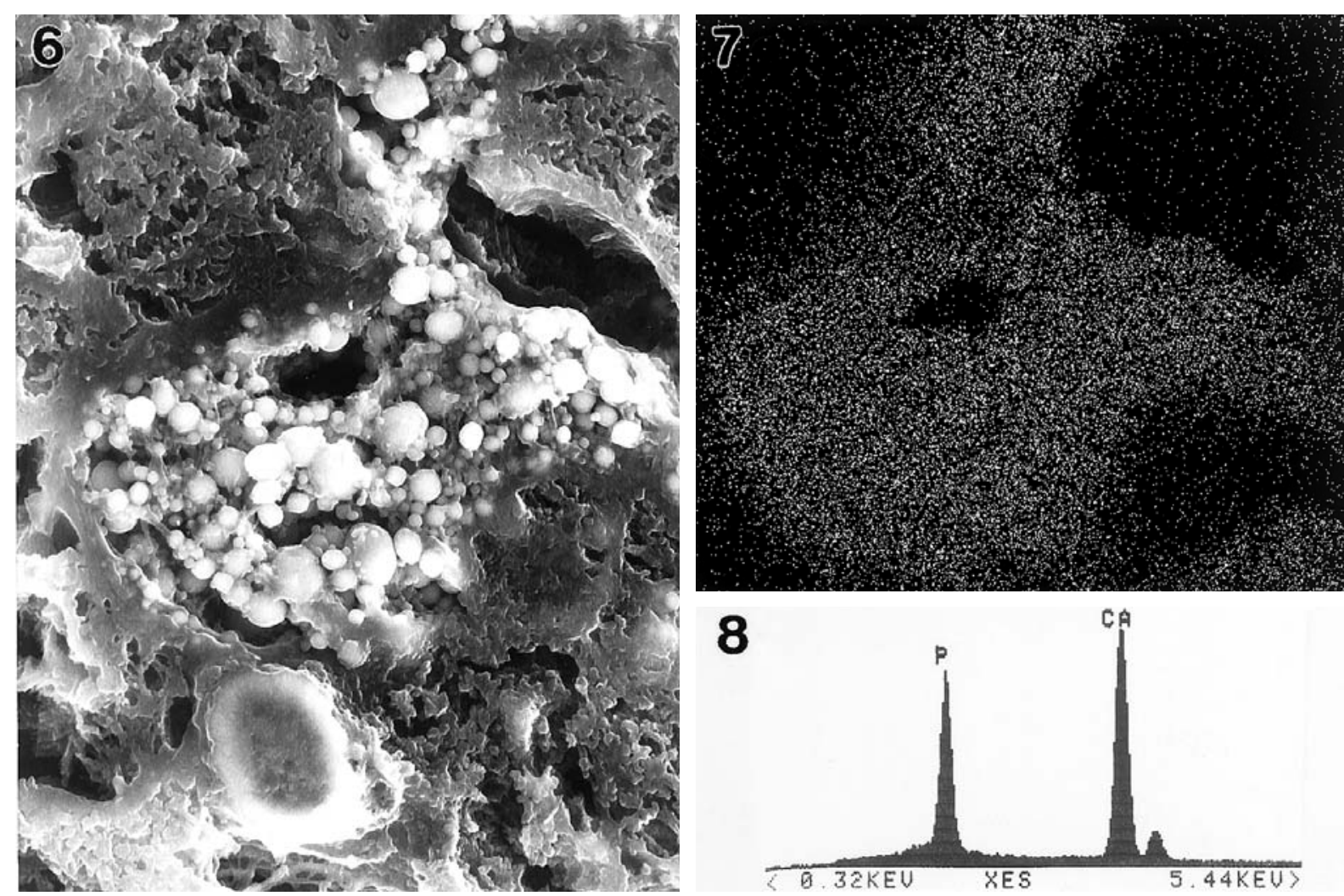

Fig.6: Many globular masses in the intercellular stroma (Secondary electron image, $\times 5,000$ )

Fig.7: Radiograph, the same area of Fig. 6 ., showing globules contain abundant calcium $(\mathrm{Ca}-\mathrm{K} \alpha$ radiograph, $\times 5,000)$

Fig.8: Electron probe microanalysis of the calcified globules showing a composition of calcium and phosphorous.

\section{Acknowledgment}

The anti-osteopontin-antibody MPIIIB 10 (1), developed by Drs. Solursh, M. and Franzen, A., was obtained from the Developmental Studies Hybridoma Bank maintained by the University of Iowa, Department of Biological Sciences, Iowa City, IA 52242, USA.

\section{References}

1. Yamazaki T, Kotani A and Kawakami T. Basal cell adenoma of the sublingual gland. J Oral Maxillofac Surg 1987; 45: 270 $-3$.

2. Kawakami T, Hasegawa H, Antoh M, et al. Ultrastructure of microcalcifications in oral neoplasms. J Hard Tissue Biol 1993; 2: 22-9.

3. Kawakami T, Nakamura C, Hasegawa H, et al. Ultrastructure of stromal calcification in mucoepidermoid carcinoma. Jpn J Oral Biol 1986; 28: 217-22.

4. Kawakami T, Hasegawa H, Nakamura C, et al. An electron microscopic observation of Psammoma body-type microcalcifications in a case of intraosseous neurinoma. J Clin Electron Microsc 1988; 21: 167-71.

5. Hirata S, Ito A, Nagoshi J, et al. Expresion of bone matrix protein messenger ribonucleic acids in human breast cancers. Possible involvement of osteopontin in development of calcifying foci. Lab Invest 1995; 72: 64-9.

6. Saavedra RA. The roles of autophasphorylation and phosphorylation in the life of osteopontin. BioEssays 1994; 16: 913-8.
7. Mark MP, Prince CW, Gay S, et al. 44-KDal bone phosphoprotein (osteopontin) antigenicity at ectopic sites in newborn rats: Kidney and nervous tissues. Cell Tissue Res 1988; 251: 23-30.

8. Nomura S, Wills AJ, Edwards DR, et al. Developmental expression of 2 ar (osteopontin) and SPARC (osteopontin) RNA as revealed by in situ hybridization. J Cell Biol 1988; 106: $441-50$.

9. Liaw L, Almeida M, Hart CE, et al. Osteopontin promotes vascular cell adhesion and spreading and is chemotactic for smooth muscle cells in vitro. Circ Res 1994; 74: 214-24.

10. Hirata S, Asada H, Kohri K, et al. Possible role of osteopontin in deposition of calcium phosphate in human pilomatricomas. $J$ Invest Dermatol 1995; 105: 138-42.

11. Hirota S, Nakajima Y, Yoshimine T, et al. Expression of bone-related protein messenger RNA in human meningiomas: Possible involvement of osteopontin in development of psammoma bodies. J Neuropathol Exp Neurol 1995; 54: 698-703.

12. Hirota S, Imakita M, Kohri K, et al. Expression of osteopontin messenger RNA by macrophages in atherosclerotic plaques. Am J Pathol 1993; 143: 1003-8.

13. Brown LF, Papadopoulos-Sergiou A, Berse B, et al . Osteopontin expression and distribution in human carcinomas. Am J Pathol 1994; 145: 610-23.

(Accepted for publication October 23, 1998) 